\title{
DESIGN ESTRATÉGICO: ORIGENS E DESDOBRAMENTOS
}

\author{
Karine de Mello Freire \\ PPG Design Unisinos \\ kmfreire@unisinos.br
}

\begin{abstract}
Resumo: 0 artigo apresenta a aproximação entre design e formulação das estratégias, as características do design úteis às estratégias organizacionais e os métodos para projetar essas estratégias, tendo como linha condutora a pesquisas desenvolvidas pela escola italiana Politecnico di Milano. Como resultado, identifica-se o design estratégico como um processo para capaz de ativar os diversos atores envolvidos na formulação das estratégias organizacionais. É uma atividade projetual coletiva desenvolvida a partir da identificação das competências distintivas da organização e da identificação de oportunidades presentes no atual ambiente no qual esta se inserirá.
\end{abstract}

Palavras-chave: design estratégico, estratégias, cenários orientados pelo design.

\begin{abstract}
The paper presents the approach of design to strategies' formulation, the design characteristics useful to organizational strategies and methods to design such strategies, having as conductive research guideline Italian's the work developed at Politecnico di Milano. As a result, we identify strategic design as a process able to activate the various actors involved in the formulation of organizational strategies. It is a collective design activity developed from the identification of organization's distinctive competencies and identifying opportunities presented in the current environment in which it will be inserted.
\end{abstract}

Keywords: strategic design, strategy, design-oriented scenarios

\section{INTRODUÇÃO}

Desde os primórdios, a área de design intermedia a relação entre o sistema sociocultural e o sistema produtivo. Utilizando os conhecimentos de tecnologias, materiais, estética e processos - criativos, de produção e de distribuição - o design é capaz de criar ofertas para atender às demandas desse sistema sociocultural em constante transformação. A partir desses conhecimentos, estabelecia-se a forma, a função, o significado e o valor das ofertas, cuja característica predominante era a materialidade. Neste período, a atividade de design era reconhecida por 
pesquisadores da área da Administração como um instrumento que podia ser usado para diferenciar os produtos dos concorrentes, garantindo uma vantagem competitiva para a organização (Kotler e Rath, 1984). Essa leitura instrumental da atividade, feita por pesquisadores externos a área, estava atrelada ao entendimento de design como 'estilo', capaz de agregar valor ao final do processo de desenvolvimento de novos produtos. A partir dos desdobramentos da chamada terceira revolução industrial, ao final dos anos 90 , pesquisadores do campo do design vislumbraram outra contribuição da atividade para organizações: um processo capaz de impulsionar a aprendizagem organizacional e de guiar o processo de desenvolvimento de estratégias organizacionais (Zurlo,1999).

Pesquisadores como Rachel Cooper (Reino Unido), Kathryn Best (Reino Unido), Thomas Lockwood (Estados Unidos), Brigite Borja de Mozota (França) apresentam reflexões importantes sobre o papel estratégico do design para as empresas, mas de uma matriz de pensamento cultura da gestão do processo de design. A escola italiana do Politecnico di Milano, pelos pesquisadores Francesco Mauri, Ezio Manzini e Francesco Zurlo abordou esse mesmo papel do design da matriz de pensamento da cultura de projeto. No Brasil, Claudio Magalhaes pesquisa a aproximação do design industrial a estratégia das próprias industrias, a partir do pensamento da gestão (Cooper e Press, 1995; Best, 2006; Mozota, 2003; Magalhaes, 1997).

O presente artigo busca por meio de uma revisão de literatura discutir o conceito de design estratégico, a partir da matriz de pensamento da cultura de projeto. Por isso, parte dos estudos de Zurlo (1999; 2010; 2012) e Meroni (2008) para identificar tais origens do conceito. A partir disso, apresenta as capacidades do design úteis a atividade estratégica e os métodos projetuais usados para a formulação das estratégias.

\section{Origens}

Francesco Zurlo (1999) dedica-se em sua pesquisa de doutorado a sistematizar o discurso de pesquisadores que abordam o tema das estratégias organizacionais associados ao design. Como resultado, o autor apresenta as competências da cultura de projeto úteis ao desenvolvimento das estratégias organizacionais e identifica uma abordagem metodológica para esse tipo de projeto. Essa maneira específica de entender a contribuição do design para as organizações é nomeada de design estratégico.

O ponto de partida de Zurlo (1999) para a definição do conceito de design estratégico é o entendimento da comunidade científica do Politecnico di Milano, dos pesquisadores Francesco Mauri e Ezio Manzini:

\footnotetext{
"o design estratégico é uma atividade de projetação na qual o objeto de projeto é o conjunto integrado de produto, serviço e comunicação (sistemaproduto) com a qual uma empresa se apresenta ao mercado, se coloca na sociedade e dá forma a própria estratégia" (Mauri, 1997 apud Zurlo, 1999; p. 9).
}

“O design estratégico é uma atividade projetual na qual o objeto é a interface empresa-cliente-sociedade e no qual o objetivo é a convergência 
do ponto de vista da empresa, do cliente, dos outros skakeholders em um único processo de coprodução de valor. Isto significa uma inovação do sistema produto, que envolve uma reconfiguração da interface entre empresa, mercado e sociedade" (Manzini, 1999 apud Zurlo, 1999; p.10).

Zurlo (1999) estabelece que, no contexto da complexidade e das redes de coprodução de valor, as estratégias organizacionais precisam ser definidas à luz de conceitos que não estejam associados a lógica da competição e da guerra (p.189): "se estratégia permite a empresa definir sua identidade, através de um processo que ativa a sua arquitetura na criação de sentido, não é mais sustentável usar a analogia com a guerra". Assim, para discutir a atuação estratégica do design o autor parte da compreensão da teoria dos jogos e das formas organizacionais cooperativas. Zurlo (1999) se vale dos autores: John Kay (1993) para definir o conceito de estratégia; Normann e Ramires (1993) para operacionalizar esse conceito a partir das novas formas organizacionais de produzir valor; e Karl Weick (1995) para definir a atividade de organizar.

Kay (1993) caracteriza a estratégia como resultado de um mix de capacidades distintivas (inovação, arquitetura e reputação) que podem levar a empresa construir estratégias competitivas e alcançar uma vantagem competitiva sustentável. $\mathrm{O}$ autor identifica que o sucesso corporativo é resultado de uma cuidadosa avaliação das forças da firma e do ambiente econômico que ela enfrenta e por isso, sua estratégia deve ser adaptativa e oportunista. Para tanto, a firma deve constantemente buscar informações do ambiente, reavaliar seu sistema organizacional e gerar conhecimento. Desta compreensão do processo de definição de estratégias como resultado de aprendizagem organizacional, Zurlo (2010) identifica uma capacidade do design útil a criação das estratégias: a sua capacidade de leitura dos ambientes.

\footnotetext{
“O design, por sua natureza, sabe interpretar a complexidade, capturando dela estruturas de sentido; sabe indicar um caminho, tornando-o visível; e sabe comunicar e gerir os processos de compartilhamento das escolhas dentro da organização"
}

Kay (1993) ressalta que vantagens competitivas devem ser sustentáveis e apropriadas. Ou seja, a capacidade distintiva deve derivar de uma característica que a firma possui e seus competidores não, capaz de trazer benefícios para a firma ao longo do tempo. Por exemplo, o autor propõe que a inovação por si mesma não necessariamente é uma vantagem competitiva apropriada. Ela está associada a capacidade da empresa de gerar novos produtos ou processos e dificilmente se sustenta nos casos em que a proteção da inovação por patentes não é possível. 0 autor aponta que a maneira mais efetiva de transformar inovação em vantagem competitiva é aliá-la a outras alavancas estratégicas como a arquitetura ou a reputação. Sendo a arquitetura definida como o conjunto de contratos relacionais entre as diversas partes - cadeia produtiva e sistema de usuários - que contribuem para a construção de valor da oferta. É o componente estratégico que reavalia o relacionamento, a confiança, a cooperação e que delineia a empresa como uma entidade integrada ao ambiente e identificável como comunidade. E reputação são os signos, símbolos e processos que contribuem para construir a integridade da empresa e a criação de confiança, ou seja, ligados à identidade da empresa. O autor ressalta que um importante elemento da estratégia de muitas firmas tem sido a transformação 
de uma capacidade distintiva inicial baseada na inovação ou arquitetura para uma mais duradoura derivada da reputação (Kay, 1993).

Partindo desse filtro para a leitura de estratégia, Zurlo (1999) identifica no sistema milanês, a alavanca estratégica das empresas que possuem vantagens competitivas sustentáveis: a arquitetura. E consegue identificar o potencial do design estratégico nesse tipo de organização: " o design estratégico encontra plena expressão nas empresas em que dentre as estratégias possíveis implementam a que alavanca a arquitetura" (Zurlo, 1999; p.150). A importância da arquitetura para o sucesso dessas empresas é reforçada por Verganti (2009) quando apresenta as inovações dirigidas pelo design estudando o mesmo sistema de design milanês. O autor denomina essa relação entre os atores da constelação de valor (componente arquitetura) de "design discourse".

E mais, essas empresas contam também com a alavanca da reputação como fontes de vantagens competitivas. Zurlo (1999; $p$ 186) declara que na empresa contemporânea a estratégia é "um processo coletivo de construção de sentido". 0 autor explica que a estratégia global ativa o ambiente em que vive o sistema de usuários para conferir sentido e construir valor, por meio de um processo interativo (comunicativo e relacional), sobre a base de uma plataforma comum composta de valores e normas compartilhadas. Esse pensamento também é compartilhado por Meroni (2008). Para a autora, a atividade de design estratégico confere as organizações sociais e de mercado um sistema de regras, crenças, valores e ferramentas para lidar com o ambiente externo e ser apto a evoluir (e dessa forma sobreviver) bem como manter e desenvolver sua própria identidade.

\footnotetext{
"A estratégia é diálogo e confronto, conversa e negociação entre múltiplos atores, e visa alcançar alguma forma de sucesso (um resultado que tem sentido para alguém)". Zurlo (2010)

“o dialogo estratégico é uma constante nessa abordagem do design em todo o projeto: do problem setting ao problem solving. O contrabriefing é uma questão de diálogo estratégico; co-design é uma questão de diálogo estratégico; visões compartilhadas são questões de diálogo estratégico". Meroni (2008, p.36)
}

Zurlo (1999) aproxima o processo de criação de estratégias da proposição do modelo de constelação de valor de Normann e Ramires (1993). Nesse modelo, os autores presumem que o valor de uma oferta seja coproduzido por diferentes atores (fornecedores, parceiros de negócio, consumidores) em um conjunto não-linear de atividades, desenvolvidas em ações recíprocas desses atores. O cliente também é envolvido neste sistema, pois suas respostas em relação ao uso das ofertas, são retroalimentadas para a constelação de atores, podendo gerar modificações nas mesmas. Zurlo (1999; p 65) aponta que "o sistema de valor que diferencia a oferta da empresa possui um forte componente projetual" ou seja, está associado ao projeto da alavanca estratégica arquitetura.

Ainda, o autor propõe que o foco de estudo do design estratégico é a ação estratégica desencadeada pelo design:

O design estratégico manifesta-se, mesmo em diversas formas, como uma atividade de projeto, com o objetivo de ativar a ação estratégica dentro de 
estruturas organizacionais. Se, como visto, a estratégia é processo de criação de sentido, então esta capacidade é ligada substancialmente à habilidade de design no criar efeitos de sentido. (Zurlo, 2010)

Ao considerar as organizações como espaços de criação de efeitos de sentido, o autor delimita esses espaços pelo conjunto de vínculos que precisa ser estabelecido pelas organizações para condicionar e limitar as atividades dos sujeitos que nelas operam. Assim, um desdobramento importante da ação estratégica é a atividade de organizar os recursos. Zurlo fundamenta no autor Weick (1995) a definição dessa atividade. Weick (1995) estabelece que organizar significa criar um sentido, um contexto, uma plataforma que seja válida para todos os sujeito envolvidos na produção de valor. Portanto, ao constituir essa plataforma, se constrói o sentido que irá apoiar a tomada de decisão de todos os atores de uma constelação de valor.

Dessas reflexões, destaca-se que o design estratégico considera que o agir projetual do design é a base para conformar as três alavancas estratégicas capazes de garantir vantagens competitivas sustentáveis para as organizações.

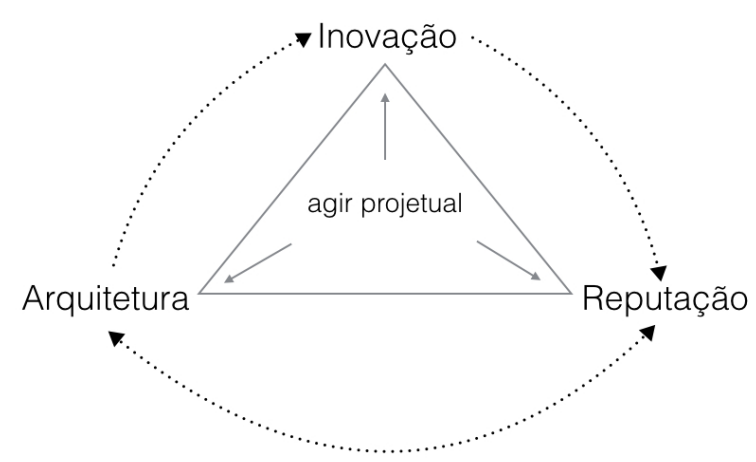

Figura 1: Relação das alavancas estratégicas na configuração de vantagens competitivas sustentáveis.

Fonte: elaborado pela autora

Deste ponto, Zurlo (1999) retoma a definição de Mauri (1996) sobre o agir projetual na ação estratégica dirigida pelo design. Mauri (1996) assume que o projeto da estratégia é concebido por meio de um agir projetual transdisciplinar capaz de conectar pontos de vista diferentes e de tecer competências e funções interdependentes. Ainda, o autor indica que usar o atributo estratégico para a atividade de design traz duas implicações: apontar a contribuição disciplinar específica e assumir uma abordagem complexa, reconhecendo ser parte de um sistema de interrelações com outros âmbitos cognitivos e funcionais. Assumindo essa abordagem,

"o projeto é pensado, como saber transformador do sentido do mundo, fundado sob a capacidade de uma nova visão, não a que vê pela primeira vez as coisas, mas que as enxerga e trata de um outro modo, como se fosse pela primeira vez, descobrindo-as diferentes e novas. O projeto, cujo elemento constituidor é a abertura ao possível, deve ser visto como evento aberto a uma nova ordem de conexões. (p.28)

"pensar em termos não lineares não significa, portanto, construir planos para o futuro, mas identificar problemas, questões, ver oportunidades no presente. Sem querer desvalorizar a criatividade nos seus aspectos adaptativos de problem solving, pensamos que o coração da inovação 
comece a bater antes da busca por soluções, no próprio momento da descoberta e do reconhecimento do problema" (p.35)

Para esses autores, o design passa a ser visto não como função organizacional, mas como um processo integrado dentro de uma comunidade organizada capaz de gerar e transformar conhecimento dentro dinâmicas complexas que envolvem toda a organização.

Disso, Zurlo (1999; p. 214) afirma que "em nível teórico, a principal característica do design estratégico é contribuir para a definição do desenho principal da comunidade ${ }^{1}$. Além disso, cria as condições para construir relações instituindo um ambiente dotado de sentido". Atuando no âmbito coletivo, o design estratégico tem o papel de ativar o processo de criatividade nas organizações catalizando novos conhecimentos para gerar inovação e a disponibilidade de troca. E considerando que a organização está inserida em redes de coprodução de valor, o design estratégico ativa a rede de stakeholders, funcionários e cidadãos para cocriarem o valor.

O design estratégico é conectado a ideia de uma capacidade transcendente do projeto tradicional, de uma atitude de ir além do que são os "objetos" de projeto para afetar os rumos estratégicos de uma empresa (Cautela, 2007). O design assume um papel estratégico quando dialoga diretamente com quem toma decisões e contribui para a "a construção da identidade empresarial, isto é, da interface que a empresa possui com a sociedade e o mercado" (Zurlo, 1999; p. 211). Está nesse sistema porque tem capacidades integrativas e de apoio a atividade estratégica do gestor e do empreendedor. E mais, a atividade de design estratégico:

"se configura como um processo social dentro da organização, não existe um indivíduo que faz o design estratégico, mas existe um grupo que, graças as capacidades da projetualidade, configuram uma atividade de design estratégico" (p.215)

E como resultado, a atividade de design estratégico:

"gera um efeito de sentido (que é a dimensão de valor para alguém), concretizando este resultado em sistemas de oferta, mais do que em soluções pontuais, em um produto-serviço mais do que em um simples produto, que é a representação visível da estratégia" Zurlo (2010)

Ainda, o autor acrescenta que o design estratégico ao gerar efeitos de sentido:

\footnotetext{
"intervém em outros aspectos que incidem nos comportamentos e na motivação dos indivíduos. Tratam-se de aspectos culturais ligados a elementos materiais e imateriais, a símbolos, a rituais específicos, que são próprios de qualquer atividade humana e que se concretizam no estilo interior que a organização decide ser" (Zurlo, 2010).
}

Assim, podemos afirmar que os objetos de projeto no qual o design estratégico opera são os ambientes culturais, físicos e relacionais nos quais uma organização apresenta o sentido (a sua razão de existir) e entrega seu valor para os diversos públicos.

\footnotetext{
${ }^{1}$ A comunidade é composta pelos atores que fazem parte do ambiente de referencia de uma organização, que extrapola os limites tradicionais desta. (p.213)
} 
Considerando o processo de formulação das estratégias como um processo social da organização, na qual a empresa define suas interfaces de interação com a sociedade e o mercado, a partir de uma análise do ambiente externo, das forças internas da organização e de uma forma de raciocínio que busca minimizar as incertezas e reduzir os riscos implícitos nestas, pode-se identificar uma forte aproximação do pensamento projetual e do pensamento estratégico. A partir dessa compreensão do processo de formulação das estratégias, discutiremos as características da cultura de design úteis a esse processo.

\subsection{Cultura de design e formulação de estratégias}

Diferentes pontos de vista aproximam a cultura de design das estratégias organizacionais. Se entendermos estratégias como comportamento inovador das organizações, identificamos em Maldonado (1971) uma das primeiras aproximações entre as culturas. $\mathrm{O}$ autor aponta que as semelhanças do agir projetual e inovador seriam: a probabilização do risco implícito em cada incerteza, a identificação do maior risco que se possa imaginar.

Para Mauri (1996) a transdisciplinaridade como instrumento para enfrentar a multidimensionalidade caracteriza a estratégia como projeto coletivo. A participação em um projeto coletivo começa com uma abertura do sujeito à alteridade. Isso se traduz em uma disposição ao envolvimento ativo e consciente nas relações estabelecidas e que assume a forma de aprendizagem, descoberta do outro como diferente de si.

Bonsiepe (2011; p.25) afirma que projetar "significa expor-se e viver com paradoxos e contradições, mas nunca camuflá-los sob o manto de harmonizações". 0 ato de projetar deve assumir e desvendar essas contradições, com uma consciência crítica, que é um passo indispensável para a prática projetual. A consciência crítica é apontada por Maldonado (1971) como o motor fundamental da práxis que antecipa o futuro, ou seja, da práxis projetual. Maldonado (1971) aponta que nem sempre o comportamento projetual leva a inovação

\footnotetext{
"se o comportamento projetual está sempre orientado para a avaliação crítica do problema que encara, isso não se verifica sempre para o comportamento inovador. $\mathrm{E}$, por outro lado, mesmo o comportamento projetual, apesar de todos os seus estrategemas de informação e decisão, só raramente atinge a inovação. Deste modo escapa-se à tentação deleitosa de imaginar que tal comportamento é o caminho real que nos leva infalivelmente à inovação. (Maldonado, 1971; p.73)"
}

No entanto, autores como Celaschi (2007) e Verganti (2009) associam o agir projetual, no nível estratégico, ao processo de inovação. Para eles, o agir projetual governa o processo de inovação.

Para Zurlo (2010) o elo de aproximação da cultura de design da formulação das estratégias é a dimensão da criação de sentido. O design, por seu caráter transdisciplinar, é capaz de conectar pontos de vista diferentes, tecendo competências e funções interdependentes. (Mauri, 1996; Cautela e Zurlo, 2006; Zurlo, 2010). E reforça o componente crítico da práxis projetual, como um aspecto importante da atividade de design estratégico: 
O contrabrief coloca-se em modo interlocutório e crítico em relação aos pedidos da empresa para analisar e compreender as razões que o geraram. É a tentativa de conhecer as razões do brief (a reason why) e dar uma contribuição, estratégica. É a abordagem [...] para levar uma própria contribuição específica, uma visão pessoal própria. Mesmo se não for convidado. Esta capacidade crítica deriva muitas vezes de um posicionamento em continuidade e familiaridade com a organização, mas externo a esta.

O projeto coletivo da estratégia, baseado na diversidade dos saberes e competências, requer uma figura que desempenhe o papel de catalizador e organizador do projeto. E o design por sua cultura projetual capaz de articular diferentes saberes e dar forma as ideias pode ser essa figura. Mauri (1996) sugere que o design pode assumir esse papel, por conta de suas competências peculiares: uma disposição à intuição e à sensibilidade perceptiva e estética; uma capacidade de escuta, de imaginação, de pesquisa da inovação e de recusa pela solução óbvia. E pela sua habilidade de tornar o pensamento visível. Zurlo (1999) também identifica o design líder desse projeto coletivo pelas capacidades: de leitura e interpretação da realidade, de projetação de caminhos possíveis a partir dessa interpretação e de tornar visíveis e compartilháveis essas visões de mundo, de forma que todos atores responsáveis pela criação de estratégias partilhem dessa visão. Outras competências apontadas pelos autores são (Mauri, 1996; Cautela e Zurlo, 2006; Zurlo, 2010):

- a sensibilidade para interpretação dos sinais fortes e fracos provenientes seja do mundo do consumo, sociocultural, seja do mundo produtivo e organizacional, interpretando a complexidade e capturando dela estruturas de sentido;

- capacidade de coordenação do conhecimento entre uma empresa e a rede;

- a criatividade, ou seja, capacidade combinar o conhecimento em formas diversas;

- a competência morfológica que estabelece a estrutura e a função das coisas;

- a capacidade de visualizar (capacidade técnica, comunicativa e relacional);

- a tradução dos sinais representativos da contemporaneidade em cenários de intervenção projetual, tornando visíveis os caminhos estratégicos possíveis

- capacidade de subverter - eliminar a inércia cultural ao ver as coisas a partir de um ponto de vista não convencional, vislumbrando o novo e o conveniente (para a empresa, sociedade e ambiente) de diferentes horizontes, resultando em uma visão crítica da realidade

- sabe comunicar e gerir os processos de compartilhamento das escolhas dentro da organização).

A partir da compreensão das competências do design úteis ao design estratégico, Zurlo (1999) aponta alguns métodos de design úteis a esse projeto coletivo. A seguir, abordaremos os métodos relacionados a capacidade de leitura do ambiente, e a capacidade de definição de cenários de intervenção projetual.

\subsection{Métodos do design estratégico}

Zurlo (1999) identifica o método "experience-based design" de John Cain (1998) como uma forma de organizar a capacidade de leitura dos sinais do ambiente no qual o design estratégico opera, no tempo presente. 


\begin{abstract}
"O experience-based design é um método para examinar, interpretar e organizar a experiência cotidiana das pessoas de uma maneira que seja útil para os envolvidos no processo de desenvolvimento de produtos e serviços - estrategistas, gestores de produtos, designers, gestores de marketing, engenheiros e tecnólogos" (Cain, 1998; p12).
\end{abstract}

Cain (1998), ao propor o método experience-based-design, sugere uma reorganização do processo de design em torno da compreensão das empresas, de seus produtos e serviços, e das experiências das pessoas que com elas interagem. Sua definição do método é: "um processo que emprega uma profunda compreensão do uso e experiência cotidiana das pessoas com os produtos e os serviços, aplicando-o para informar e moldar os objetivos do negócio" (Cain, 1998; p. 11).

$\mathrm{O}$ autor defende que esse método melhora os resultados de design, visto que integra o processo em torno de um princípio orientador: a ação das pessoas nas situações reais de uso ou das experiências. São as experiências das pessoas, o cerne do projeto, que devem moldar e direcionar a estratégia, o desenvolvimento e a implementação de novos produtos e serviços. O autor enumera os componentes da experiência como: (1) os sistemas socioculturais, que informam ideias, crenças, atitudes e expectativas dos usuários (think); (2) os padrões e as rotinas de ação, com significados e identidade (do); (3) as coisas que as pessoas usam e o impacto que estas têm naquilo que os indivíduos pensam e fazem (use).

Por meio desses três componentes, é possível descrever as relações entre objetos, ambientes e pessoas e construir frameworks de como as pessoas se relacionam e experienciam alguns aspectos do seu mundo. Para tanto, Cain (1998) propõe que sejam usadas técnicas de pesquisa etnográficas capazes de observar, descrever e sintetizar essas relações. Porém, diferentemente de antropólogos, que buscam apenas entender as experiências, os designers buscam conhecê-las para "ter condições de mudá-la, melhorá-la" (Cain, 1998, p. 13). Designers buscam sempre identificar oportunidades de transformar as realidades existentes em outras mais desejáveis para os agentes sociais que (con)vivem nas sociedades. Para o autor, a construção de frameworks é essencial para a inovação, pois estes são a síntese que serve como uma ponte entre o existente e o desejável. Os frameworks devem ser o fundamento que guia os dois primeiros objetivos do método que será apresentado a seguir. E, ainda, servem para identificar os aspectos relevantes que podem afetar positiva ou negativamente a experiência e auxiliar a etapa de concepção de soluções.

O método experience based design é composto por quatro objetivos, que servem para guiar a equipe do problema a forma final, quais sejam: (1) definir e estruturar o problema em termos da experiência dos usuários; (2) identificar oportunidades de mudar as experiências atuais; (3) inventar as soluções; (4) criar personificação da solução, formas tangíveis que dão vida e expressão às soluções.

Zurlo (1999) indica que o design estratégico pode propor caminhos de inovação por meio do planejamento por cenários, mas não apresenta um método que articula a capacidade de leitura do ambiente e a proposição de cenários futuros.

\footnotetext{
"o design estratégico permite propor inovação hipotizando novos contextos de uso e de comportamento por meio da técnica de planejamento por cenários. O planejamento de cenários permite focar alguns futuros possíveis e os fatores que podem influenciá-lo. Isto é um pensamento estratégico" (Zurlo, 1999; p.72).
} 
A partir dessa compreensão, propomos que os frameworks das experiências de Cain (1998) podem ser a base a construção de cenários projetuais, na medida que conectam os contextos de uso existentes aos futuros desejáveis. São as constantes culturais do passado e do presente que devem permanecer no futuro.

Os cenários projetuais são construídos a partir da leitura qualitativa dos sinais da contemporaneidade, que podem ser capazes de moldar o futuro (Manzini e Jegou, 2003):

\footnotetext{
"não importa quantas pessoas estão fazendo algo hoje, se nós formos bons o suficiente para torná-lo atraente e potencialmente viável, ele pode moldar o futuro. 0 futuro será o resultado do que produzirmos de agora em diante a partir das premissas que encontramos nos sinais do presente"
}

Embora existam outros autores que proponham o metaprojeto como método para construção de cenários para a inovação (Celaschi ,2007), a proposta de Manzini e Jegou (2006) foi escolhida por estar alinhada ao que Zurlo (1999; 2010; 2012) propõe em seus trabalhos.

Manzini e Jegou (2006) partem do principio que as organizações produtivas e sociais de tempo em tempo precisam reconfigurar suas próprias atividades. E para tal, devem operar de forma sistêmica, envolvendo múltiplos atores internos e externos à organização. A maneira apontada pelos autores para promover o diálogo estratégico entre esses atores é a produção de cenários, pois permite desenvolver uma visão compartilhada e motivada comum a todos os envolvidos. É uma metodologia que apoia a tomada de decisão estratégica e que fornece insumos para promover a inovação do sistema em contextos turbulentos e complexos.

Os autores caracterizam os cenários como uma visão plausível e passível de discussão de um estado hipotético das coisas, descritas de modo compreensível comunicável. É uma simulação projetual no qual se inserem artefatos inexistentes, mas possíveis, de modo a favorecer a discussão e a avaliação dos seus pressupostos e implicações, pelos atores envolvidos no diálogo estratégico, para se chegar a um ponto convergente de opiniões. Uma visão de futuro que não promova esse tipo de diálogo entre os atores sociais não é um cenário. Um cenário orientado pelo design (Designorienting scenarios - DOS) é definido como uma visão motivada e articulada com a finalidade de catalisar a energia dos diversos atores envolvidos no processo projetual, de forma que seus esforços sejam direcionados a essa visão comum.

Os cenários se configuram como um mundo de referência possível em termos de contexto e situações de uso. É uma narrativa visual e textual que organiza todo o material coletado e inspira o percurso de inovação da organização. São visões compartilháveis que traduzem informações e intuições em conhecimento perceptível (Meroni, 2008).

Em síntese, Manzini (2003) aponta como características do cenário orientado pelo design: a pluralidade, exequibilidade, microescala, expressão visual e participação. Ou seja, na sua construção, são considerados os contextos alternativos nos quais os aspectos ambientais, socioculturais e econômicos possam ser avaliados, baseados em tecnologias existentes ou oportunidades socioculturais identificadas. São definidos pela escala do contexto de vida das pessoas, expressando visualmente os contextos e as propostas, para que um conjunto de atores participe de um projeto coletivo a partir de um ponto de vista compartilhado. 
Por isso, um cenário deve ser composto por três elementos: visão, motivação e proposta. A visão de um cenário deve responder a questão "como seria o mundo se...?" por meio de uma narrativa, apresentando uma imagem sintética de como seria o estado das coisas se uma sequencia de eventos acontecesse. A imagem apresenta como o contexto pode se configurar se certos comportamentos fossem introduzidos, certas ações acontecessem e certas propostas de produtos e serviços fossem adotadas. Ou seja, apresenta um espaço físico e sociocultural no qual um grupo de pessoas e seus comportamentos poderão ser coerentemente imaginados com um conjunto de artefatos e ações. A motivação é o componente que legitima a existência do cenário e lhe confere significado. Na construção dos cenários, a motivação apresentada pela explicitação das premissas e das condições do entorno adotadas para a sua construção e com quais critérios e instrumentos as diversas alternativas poderão ser avaliadas. A proposta é o componente que dá consistência a essa visão. Responde a questão "como se articula visão conjunta? De que coisas é composta? Como se pode implementá-la?. A proposta apresenta a indicação de um conjunto de produtos, serviços, sistemas ou soluções complexas, que possuem um traço comum, caracterizante do cenário.

Os cenários resultantes da atividade de design devem ser artefatos conceituais capazes de ajustar-se as mudanças do ambiente, como sistemas adaptativos, que são abertos e interativos, e de apreender eventos que acontecem e com base nesse aprendizado, se reorganizar. E por isso se alinham a compreensão de estratégia proposta por Kay (1993). Os cenários podem ser a base para o alinhamento da comunidade situada no entorno da oferta de uma empresa, propondo um conjunto compartilhado de valores capazes de sedimentar as relações entre os múltiplos atores do sistema. Assim, o projeto por cenários estaria associado a duas alavancas estratégicas: inovação e arquitetura, que são a base para a construção da reputação.

A figura 2 sintetiza essa processualidade dinâmica, que se adaptar e se reorganizar continuamente as mudanças ambientais, que serve como direcionador da formulação das estratégias organizacionais.

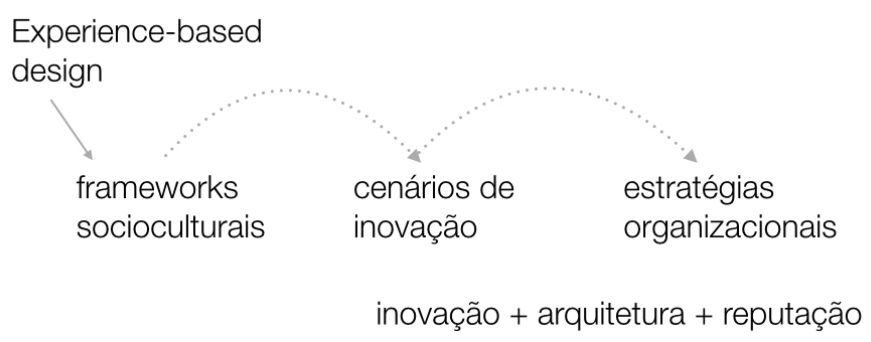

Figura 2: processualidade do projeto da estratégia

Fonte: elaborado pela autora

\section{Considerações finais}

Após apresentar as principais características do design estratégico seus métodos de abordagem, podemos propor que o design estratégico é um processo para capaz de ativar os diversos atores envolvidos na formulação das estratégias organizacionais. É uma atividade projetual coletiva desenvolvida a partir da identificação das competências distintivas da organização e da identificação de 
oportunidades existentes no atual ambiente. A cultura de design possui capacidade de leitura e intepretação dos sinais do presente, fundamentada em pesquisas qualitativas ligadas a etnografia e linguagens, sendo capaz de tornar visíveis os espaços nos quais a organização pode operar para obter vantagens com suas capacidades distintivas.

Esse conhecimento é compartilhado para que os atores possam criar coletivamente o sentido e o valor da oferta da organização. Neste projeto coletivo são expostas as contradições e conflitos que a comunidade enfrentará para que se chegue a uma visão comum, valorizada por todos os envolvidos. Esse diálogo é mediado pelo projeto de cenários construídos pelo design, que pela característica da expressão visual, facilita a visualização dos caminhos possíveis. A partir dessa visão será desenvolvido o conceito (estratégia de contextualização) que guiará os desdobramentos da estratégia em termos da configuração das interfaces da empresa com a sociedade e o mercado. Esses aspectos envolvem o estilo de relação que a empresa quer ter com essas entidades, incluindo o ambiente físico, que confere a identidade da organização e os rituais de troca entre os atores. É o projeto do sistema de trocas entre os atores de uma comunidade estabelecida a partir de valores e normas compartilhadas, cujos resultados podem ser materializados em produtos, processos e comunicações.

\section{REFERÊNCIAS}

Best, K. Design Management: managing design strategy, process and implementation. New York: AVA Publishing. 2006

Cain, John. Experience based design: toward a Science of Artful Business Innovation. Design Management Journal, v.9, n.4, Aug 24, 1998. p.10-16.

Cautela, Cabirio. Strumenti di design management. Roma: Franco Angeli,2007. 142p.

Celaschi. Flaviano Dentro al progetto: appunti di merceologia contemporanea. In: F. Celaschi e A. Deserti (Ed.). Design e Innovazione. Roma: Carocci, 2007. p.15-56

Cooper, Rachel; Press, Mike. The Design Agenda: a guide to successful Design Management. Chichester: Wiley, 1995

Kay J., Foundations of corporate success: how business strategies add value. Oxford: Oxford University Press, 1993

Kotler, Philip. Rath, Alexander. Design: a powerful but neglected strategic tool. Journal of Business Strategy, 1984. Vol. 5 Iss: 2, pp.16 - 21

Lockwood, Thomas. Design Thinking: Integrating Innovation, Customer Experience, and Brand Value. New York: Allworth Press, 2010.

Magalhães, Cláudio Freitas de. Design Estratégico. Rio de Janeiro: CNI/Senai-Cetiqt, 1997.

Maldonado, Tomas. Meio Ambiente e Ideologia. Lisboa: Socicultur, 1971

Manzini, Ezio. Scenarios of sustainable wellbeing. Design philosophy papers, v. 1, n. 1, 2003. Disponível em: http://www.desphilosophy.com/dpp/dpp_index.html 
Manzini, Ezio.; Jégou, François. Design degli scenari. In: BERTOLA, P.; MANZINI, E. Design Multiverso | Notas de fenomenologia do design. Milano: Edizioni POLI.design, 2006, pp. 189-207

Manzini, Ezio.; Jégou, François. Sustainable Everyday. Scenarios of Urban Life, Milano 2003

Mauri, Francesco. Progettare progettando strategia. Milano: Masson S.p.A, 1996

Meroni, Anna. Strategic design: where are we now? Reflection around the foundations of a recent discipline. Strategic Design Research Journal, v.1, n.1, Dec 1, p.31-38. 2008.

Mozota, Brigite. Borja. de. Design Management: Using to build brand value and corporate innovation. New York: Allworth Press, 2003.

Normann, Richard; Ramirez, Rafael. Designing interactive strategy. Harvard Business Review, n.july-august, Jan 1, 1993. p.65-77.

Zurlo, Francesco. Un modello di lettura per il Design Strategico. La relazione tra design e strategia nell'impresa contemporanea. Dottorato di Ricerca in Disegno Industriale - XI ciclo. Politecnico di Milano, Milano, 1999. 247 p.

Zurlo, Francesco. Design Strategico. In: XXI Secolo, vol. IV, Gli spazi e le arti. Roma: Enciclopedia Treccani. 2010. Disponível em: http://www.treccani.it/enciclopedia/designstrategico_(XXI-Secolo). Acesso em 30 de abril de 2014.

Zurlo, Francesco. Le strategie del design. Libraccio Editore, 2012. 49p.

Weick Karl. Sensemaking in Organizations. Sage Publications, 1997. 